\title{
Three-dimensional maturation reaction norms for North Sea plaice
}

\author{
R. E. Grift' ${ }^{1,2}$, M. Heino ${ }^{3,2,4}$, A. D. Rijnsdorp ${ }^{1, *}$, S. B. M. Kraak ${ }^{1}$, U. Dieckmann ${ }^{2}$ \\ ${ }^{1}$ Wageningen IMARES - Institute for Marine Resources and Ecosystem Studies, Wageningen UR, PO Box 68, \\ 1970 AB, IJmuiden, The Netherlands \\ ${ }^{2}$ Evolution and Ecology Program, International Institute for Applied Systems Analysis, Schlossplatz 1, \\ 2361 Laxenburg, Austria \\ ${ }^{3}$ Institute of Marine Research, PO Box 1870, Nordnes, 5817 Bergen, Norway \\ ${ }^{4}$ Department of Biology, University of Bergen, PO Box 7800, 5020 Bergen, Norway
}

\begin{abstract}
Probabilistic maturation reaction norms (PMRNs) with up to 3 explanatory dimensions were estimated for female North Sea plaice Pleuronectes platessa. The 3-dimensional PMRNs reported here (1) are the first to be obtained for any organism, (2) reveal the differential capacity of alternative life-history state variables to predict the onset of reproduction, (3) document consistent temporal trends in maturation, and (4) help disentangle the contributions of genetic and plastic effects to these trends. We first show that PMRNs based on age and weight provide slightly more accurate approximations of maturation probabilities than PMRNs based on age and length. At the same time, weight-based PMRNs imply a much wider spread of maturation probabilities than lengthbased PMRNs. We then demonstrate that including condition as a third explanatory variable improves predictions of maturation probability. The resultant 3-dimensional PMRNs for age-lengthcondition or age-weight-condition not only show how, at given size and age, maturation probability increases with condition, but also expose how this impact of condition decreases with age and has changed over time. Our analysis reveals several interesting temporal trends. First, it is demonstrated that even after removing plastic effects on maturation captured by age, length, weight and condition, residual trends towards maturation at younger ages and smaller lengths remain. Second, we find that the width of both length- and weight-based PMRNs decreased significantly over time. Third, age and condition are nowadays affecting maturation probabilities less than they did decades ago. We conclude that plaice are currently maturing at a very low age, size and body condition, and that the narrow and steep reaction norms do not allow a strong continuation of the observed trends. The findings obtained are in good agreement with predictions from life-history theory based on the hypothesis of evolutionary change caused by heavy exploitation.
\end{abstract}

KEY WORDS: Fisheries-induced evolution - Body condition · Probabilistic maturation reaction norms · Phenotypic plasticity $\cdot$ Maturation process $\cdot$ Pleuronectes platessa

Resale or republication not permitted without written consent of the publisher

\section{INTRODUCTION}

Combinations of ages and lengths at maturation strongly influence an individual's expected reproductive success and thus a stock's reproductive potential. Since the allocation of energy to reproduction decreases somatic growth (e.g. Reznick 1983), the tradeoff between reproduction and growth implies a trade- off between current and future reproduction which depends on the level of mortality at different life stages (Bell 1976, 1980, Heino \& Kaitala 1999). Maturation is a complex physiological process influenced by bioenergetic factors such as resource availability and body reserves, which in turn are affected by the local environment and individual experience. The age or length at which most species mature is therefore not fixed, but 
is described by a reaction norm that can be characterized either by a switch curve deterministically relating maturation age to maturation length (Stearns \& Koella 1986, Heino et al. 2002a), or rather more realistically, by curves of of age- and size-dependent maturation probabilities (Heino et al. 2002a). Sets of such maturation probabilities are known as probabilistic maturation reaction norms or PMRNs.

It is helpful to highlight that maturation reaction norms are bivariate reaction norms and thus fundamentally differ from the more widely familiar univariate reaction norms describing how a single phenotypic character varies with a single environmental variable. Maturation reaction norms, by contrast, describe how 2 phenotypic characters - age and length at maturation - are jointly affected by a single environmental variable: the average growth rate of individuals before maturation. Environmental effects are here manifested in the variation of length at age, i.e. slopes of growth trajectories. The latter may in turn depend on many other environmental variables, including temperature and the abundance of food items or of competitors: in this way, growth rates or lengths-at-age conveniently integrate a multitude of factors of the physical and biotic environment that are eminently relevant for the studied organism. This physiological integration naturally accounts for the differential impacts of and potentially complex interactions between these factors, which typically would be very difficult to distinguish empirically. Harnessing individual-level explanatory variables beyond age and length for describing maturation probabilities more accurately is conceptually straightforward (Heino et al. 2002a, Van Dooren et al. 2005) but has not been attempted before.

The selection pressures on and resulting evolution of maturation reaction norms are determined by environmental conditions such as size-dependent mortality rates (Heino \& Kaitala 1999) and resource availability (Siems \& Sikes 1998). In general, ecological settings with low survival and slow growth among potentially reproducing individuals evolutionarily favour high reproductive effort at early ages (Reznick et al. 1990, Hutchings 1993, Reznick et al. 1997). In particular, high fishing mortality imposed on reproducing fish may cause evolutionary changes in maturation reaction norms by selecting for genotypes that effectively produce more offspring under conditions of heavy fishing (Borisov 1978, Law 2000, Heino \& Godø 2002). Superimposed on these evolutionary effects of fishing, other changes in the physical and biotic environment occur, such as temperature fluctuations and changes in food conditions, which are also bound to influence the processes of growth and maturation (Law 2000). Disentangling these effects of phenotypic plasticity from any underlying genetic changes in maturation probabilities thus becomes an important challenge (Rijnsdorp 1993).

During the 20th century, maturation in the heavily exploited North Sea plaice Pleuronectes platessa L. has shifted towards younger ages and smaller lengths at $50 \%$ maturity (Rijnsdorp 1993, Grift et al. 2003). Statistical analyses show that improved food conditions caused increased growth rates during the second part of the 20th century (Rijnsdorp \& Van Leeuwen 1992, 1996) resulting in earlier maturation. Above and beyond this effect of phenotypic plasticity, evidence suggests that the maturation schedule of North Sea plaice has also undergone evolutionary changes (Rijnsdorp 1993, Grift et al. 2003). More specifically, the analysis of PMRNs for age and size at maturation (Rijnsdorp 1993, Grift et al. 2003) supports the hypothesis of fisheries-induced evolution towards lower ages and lengths at maturation and suggests a picture in which a persistent long-term trend resulting from genetic and plastic responses to faster growth are superimposed on short-term fluctuations originating from residual plastic responses. Grift et al. (2003) showed that while length was an important cue for maturation, other factors such as water temperature and food conditions may also play important roles in the maturation process of North Sea plaice.

In this article we estimate PMRNs based on different combinations of age, length, weight and condition in order to take best advantage of all information available for understanding the maturation schedules of female North Sea plaice and for disentangling genetic and plastic changes of these schedules. We thus focus on 2 aspects of the maturation process: first we describe the roles of weight and condition in the maturation process, either in place of or in combination with length, and second we use the results to investigate if the maturation process has changed due to fisheries induced change. When modelling a population's maturity status, length is most often used as a measure of size and only few studies (Cook et al. 1999, Bromley 2003) have used weight. Weight may be expected, however, to provide a more accurate cue for maturation than length, because it more directly reflects the physiological status and body reserves of fish. Reflecting the importance of bioenergetics for maturation, condition - often measured by morphometric condition indices such as Fulton's condition factor $K$ (weight per cubed length - can have a positive influence on the fraction of mature fish, as shown for salmonids (Bohlin et al. 1990, Rowe \& Thorpe 1991, Simpson 1992, Bohlin et al. 1994), walleye Sander vitreus (Henderson \& Morgan 2002), cod Gadus morhua (Marteinsdottir \& Begg 2002) and American plaice Hippoglossoides platessoides (Morgan 2004). We estimate maturation probabilities in a 3-dimensional parameter 
space, in which the effects of body size, age and condition are considered simultaneously. Several studies estimated the probability of being mature at a given age, length and condition also (Henderson \& Morgan 2002, Morgan 2004) but whereas earlier studies focused on probabilities of being mature, the PMRN approach helps to investigate probabilities of becoming mature. This means that in our analyses, confounding effects influencing maturation via growth and survival can be separated from those effects that influence maturation directly. The PMRNs with 3 explanatory dimensions presented here are the first obtained for any organism.

\section{METHODS}

North Sea plaice. Plaice Pleuronectes platessa is a sexual dimorphic iteroparous broadcast spawner following a capital spawning strategy (Rijnsdorp 1989, Rijnsdorp \& Witthames 2005). It has been a target species of the mixed demersal fisheries in the North Sea since the start of the industrial revolution in the second half of the 19th century (Rijnsdorp \& Millner 1996). Over the study period, mortality rates imposed by fishing have been high, exceeding the instantaneous natural mortality rate (of ca. $0.1 \mathrm{yr}^{-1}$ ) by a factor of 2 to 4 . From the 1950s until 1980, fishing mortality rate (Ages 2 to 10) increased from $0.2 \mathrm{yr}^{-1}$ to $0.4 \mathrm{yr}^{-1}$ after which it stabilized around this level. The exploitation pattern has been dome shaped with a peak in fishing mortality rate at Age 5 (Grift et al. 2003). Superimposed on changes in fishing mortality, food availability has increased, leading to accelerated growth of plaice smaller than $30 \mathrm{~cm}$ (Rijnsdorp \& Van Leeuwen 1992, 1996).

Data collection. We use data on female plaice from the Dutch sampling programme for landings by the fishing fleet, carried out since 1957: a detailed description of this data is provided in Grift et al. (2003). In addition to the date of landing and the geographical position of the catch, length (mm), total weight ( $\mathrm{g})$, sex, maturity stage (1: immature; 2 : ripening; $3,4,5$ : spawning; 6: nearly spent; 7 : spent; with stages 2 to 7 thus referring to mature individuals; Rijnsdorp 1989) and age (yr, using January 1 as the nominal birthday) were recorded. The age of fish was determined from the pattern of growth zones in the otoliths under the assumption that each zone corresponds to 1 yr. A stratified random subset of otoliths was used to calculate yearly length increments of individual females by using otolith back-calculations. The age determination and otolith back-calculation methods have been validated (Rijnsdorp et al. 1990).

Data selection. Only data of cohorts from 1955 onwards were used, since this cohort was the first that occurred in the sampling programme from Age 2 on- wards. Only data collected in the first quarter of each year were selected because during this period adult fish return to their spawning grounds in the southerneastern North Sea. Rijnsdorp (1989) showed that samples from commercial landings during the spawning season allow for a reliable estimate of the maturitylength and maturity-age relationships. Sample locations were restricted to the south-eastern North Sea (51 to $56^{\circ} \mathrm{N}$, east of $2^{\circ} \mathrm{E} ; 51$ to $53.5^{\circ} \mathrm{N}$, 1 to $2^{\circ} \mathrm{E}$. Data of females of Ages 2 to 6 yr were used because younger female plaice are not landed and because at Age 7 all females were mature. We only used data from female plaice, because males mature at a size well below the minimum landing size of $27 \mathrm{~cm}$ (Rijnsdorp 1989). In total, data on the length, weight, age and maturity status of 18416 females were available for analysis. For the analysis of annual length increments, back-calculated lengths of 2429 females were used from an updated dataset from Rijnsdorp \& van Leeuwen (1996).

Normalization of observed weights. Weights of mature females strongly and systematically vary within the spawning season, due to the seasonal cessation of feeding and the spawning of eggs (Fig. 1). The observed weights of mature females of different maturity stages were therefore adjusted to account for these changes. The dependence of weight $(W, g)$ on length $(L, \mathrm{~mm})$ and year $(Y)$ for the different maturity stages ( $M=2$ to 7 ) were analysed by a linear model, using log-transformed weights and lengths:

$\log W \sim \log L+F_{M}+Y+\left(\log L \times F_{M}\right)+(\log L \times Y)+\left(F_{M} \times Y\right)$

where weight, length and year are continuous variables, and the maturity stage $\left(F_{M}\right)$ of mature females is a class variable. This model describes weights well

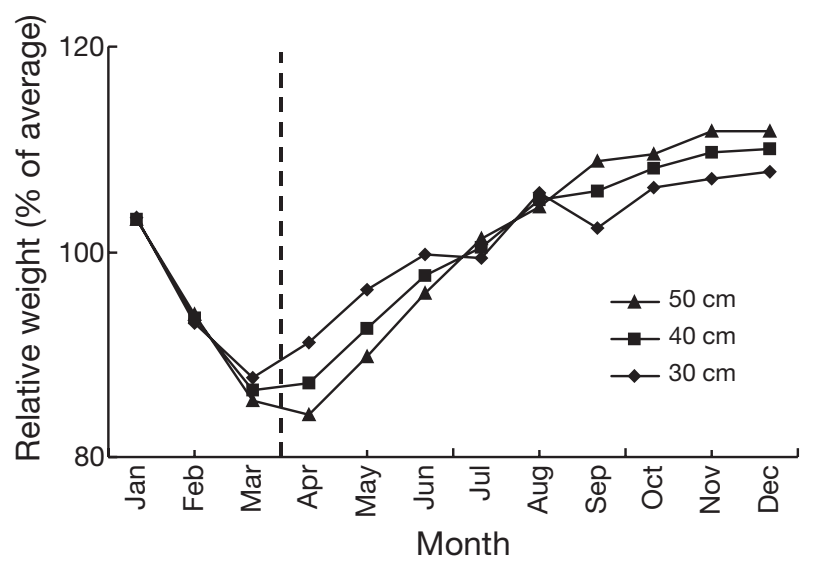

Fig. 1. Pleuronectes platessa. Seasonal changes in weight of mature female plaice for 3 given lengths. For each month and length, weights relative to yearly average weights averaged across Ages 4 to 10 and Years 1990 to 1999. Dashed line indicates the end of the period to which data used in this study were restricted (first quarter) 
$\left(\mathrm{R}^{2}=0.97,21 \mathrm{df}\right)$ and was thus used to normalize the observed weights of mature females, as if they had all been collected when in Maturity Stage 2 (ripening). In other words, the normalized weight is obtained by adding to the observed weight the difference between observed weight and weight predicted for an individual with the same length but with Maturity Stage 2 in the same year. Weights of immature fish were not corrected. In our subsequent analysis we have thus controlled for otherwise unaccounted egg mass and for the metabolic loss of body weight that occurs because plaice do not feed during the spawning season (Rijnsdorp \& Ibelings 1989).

Estimation of maturity ogives. The fraction of mature fish of a particular age or size is customarily described by maturity ogives. In our analysis, these ogives were estimated using logistic regression, with cohort, age, weight, length and condition as independent variables. Assuming a binomial error structure, the fraction of mature females $(O)$ is logit transformed, $\operatorname{logit}(O)=\log [O /(O-1)]$. Ogives were modelled using the GENMOD procedure of the SAS software system in which the log-likelihood functions with respect to the regression parameters are maximized (Allison 1999). Four ogive models were used and their performance to explain the fraction of mature females compared, to comprehensively investigate the effects of cohort, age, weight, length and condition,

$$
\begin{aligned}
\operatorname{logit}(O) \sim & L+A+F_{C}+(L \times A)+\left(L \times F_{C}\right)+\left(F_{C} \times A\right) \\
\operatorname{logit}(O) \sim & W+A+F_{C}+(W \times A)+\left(W \times F_{C}\right)+\left(F_{C} \times A\right) \\
\operatorname{logit}(O) \sim & L+K+A+F_{C}+(L \times K)+(L \times A)+\left(L \times F_{C}\right) \\
& +(K \times A)+\left(K \times F_{C}\right)+\left(A \times F_{C}\right) \\
\operatorname{logit}(O) \sim & W+K+A+F_{C}+(W \times K)+(W \times A)+\left(W \times F_{C}\right) \\
& +(K \times A)+\left(K \times F_{C}\right)+\left(A \times F_{C}\right)
\end{aligned}
$$

where length $(L)$, weight $(W)$, condition factor $(K=$ $\left.W / L^{3}\right)$ and age $(A)$ are continuous variables, and cohort $\left(F_{C}\right)$ is a class variable. The additional value of including condition in Models (4) \& (5) was statistically tested by computing a likelihood-ratio test statistic and the Akaike Information Criterion (AIC) in which Model (4) was compared to Model (2) and Model (5) was compared to Model (3). By using Fulton's condition factor we thus assumed a cubic relationship between length and weight. This assumption is reasonable because the exponent in the length-weight relationship is 3.2 for female plaice (linear model for all data, 18416 observations, $\mathrm{p}<0.0001, \mathrm{R}^{2}=0.96$ ). To check the validity of the assumption, all analyses were also executed with the length independent condition factor $\left(K=W / L^{3.22}\right)$ but this did not lead to different results or conclusions.

Whether these models were linear on the logit-scale was evaluated by testing the effects of logarithmic and square-root transformations of length and weight and by using the technique of fractional polynomials (Royston \& Altman 1994, Hosmer \& Lemeshow 2000). Logarithmic and square root transformations did not lead to an increase in the fraction of deviance explained $\left(\mathrm{R}^{2}\right)$. Fractional polynomials resulted in a significant $(\mathrm{p}<$ $0.0001)$ but very small absolute increase of $R^{2}(<0.01)$. As the parameter estimates of such a model had large standard errors (>50\%), we chose to use the generalized linear models specified above.

Estimation of probabilistic maturation reaction norms. In view of the data available for plaice, the probability of maturation at a certain age and size needs to be estimated with a method based on maturity ogives and annual size increments. Here size can be given by either length or weight: $S=L, W$. Based on the probability $O$ of being mature at age $A$ and size $S$, given by the maturity ogive $O(A, S)$, the probability $P$ of maturation at age $A$ and size $S$ is given by (Barot et al. 2004a):

$P(A, S)=[O(A, S)-O(A-1, S-\delta S)] /[1-O(A-1, S-\delta S)]$

where $(A-1)$ indicates the age previous to the one for which we estimate the probability to mature and $(S-\delta \mathrm{S})$ being the size increment between age $(A-1)$ and age $(A)$. The method assumes iteroparity, which is the case for North Sea plaice. We used length and weight as proxies for measures of size. We also considered a model where maturation probability depends on age, size ( $S$, length or weight) and condition $(K)$ :

$$
\begin{aligned}
P(A, S, K)= & {[O(A, S, K)-O(A-1, S-\delta \mathrm{S}, K-\delta \mathrm{K})] / } \\
& {[1-O(A-1, S-\delta S, K-\delta K)] }
\end{aligned}
$$

Estimation of the maturation probabilities for each cohort and age comprised 3 steps (Grift et al. 2003, Barot et al. 2004a): (A) estimation of maturity ogives; (B) estimation of annual increments in length, weight and condition; and (C) estimation of maturation probabilities and thus of PMRNs. Two further steps then consisted of (D) estimating confidence limits around the estimated PMRN midpoints using a bootstrap method, and (E) testing the significance of trends in maturation probabilities. The general rationale and assumptions underlying this procedure are described in Barot et al. (2004a, b; see also Grift et al. 2003). The 5 steps of our procedure are described in more detail below.

(A) Maturity ogives: Whereas Models (2) to (5) were used to investigate the effects of cohort, length, age, weight and/or condition on the maturation process, simpler sub-models were used for estimating maturity ogives and maturation probabilities. The model selection was based on the significance of variables $(\mathrm{p}<$ 0.05 ) and on the standard errors of their parameter 
Table 1. Pleuronectes platessa. Results of maturity ogive Models (2) to (5). $\mathrm{R}^{2}$ : deviance additionally accounted for as terms are successively introduced from one row to the next. $L$ : length; $A$ : age; $C$ : cohort; $W$ : weight; $K$ : condition factor. All terms were highly significant $(\mathrm{p}<0.001)$ except those in italics $(\mathrm{p}>0.10)$. Terms in bold were selected for maturity ogive models used in estimation of PMRNs where Models (4) and (5) were adapted such that cohort was treated as a continuous variable. Total: $\mathrm{R}^{2}$ of complete model. Total selected: $\mathrm{R}^{2}$ with selected terms only. AIC: Akaike information criterion

\begin{tabular}{|cccccccc|}
\hline $\begin{array}{c}\text { Model } \\
(2)\end{array}$ & $\begin{array}{c}\mathrm{R}^{2} \\
(\%)\end{array}$ & $\begin{array}{c}\text { Model } \\
(3)\end{array}$ & $\begin{array}{c}\mathrm{R}^{2} \\
(\%)\end{array}$ & $\begin{array}{c}\text { Model } \\
(4)\end{array}$ & $\begin{array}{c}\mathrm{R}^{2} \\
(\%)\end{array}$ & $\begin{array}{c}\text { Model } \\
(5)\end{array}$ & $\begin{array}{c}\mathrm{R}^{2} \\
(\%)\end{array}$ \\
\hline $\mathbf{L}$ & 38.5 & $\mathbf{W}$ & 43.7 & $\mathbf{L}$ & 38.5 & $\mathbf{W}$ & 43.7 \\
$\mathbf{A}$ & 1.4 & $\mathbf{A}$ & 1.1 & $\mathbf{K}$ & 6.1 & $\mathbf{K}$ & 1.1 \\
$\mathbf{C}$ & 2.2 & $\mathbf{C}$ & 2.2 & $\mathbf{A}$ & 2.3 & $\mathbf{A}$ & 2.3 \\
$\mathbf{L} \times \mathbf{A}$ & 0.2 & $W \times A$ & 0.0 & $\mathbf{C}$ & 2.7 & $\mathbf{C}$ & 2.6 \\
$\mathbf{L} \times \mathbf{C}$ & 0.8 & $\mathbf{W} \times \mathbf{C}$ & 0.7 & $L \times K$ & 0.0 & $\mathbf{W} \times \mathrm{K}$ & 0.0 \\
$\mathbf{A} \times \mathbf{C}$ & 0.6 & $\mathrm{~A} \times \mathbf{C}$ & 0.7 & $\mathbf{L} \times \mathbf{A}$ & 0.1 & $\mathbf{W} \times \mathbf{A}$ & 0.0 \\
& & & & $\mathbf{L} \times \mathbf{C}$ & 0.6 & $\mathbf{W} \times \mathbf{C}$ & 0.6 \\
& & & & $\mathbf{K} \times \mathbf{A}$ & 0.0 & $K \times A$ & 0.0 \\
& & & & $\mathrm{~K} \times \mathbf{C}$ & 0.0 & $\mathrm{~K} \times \mathbf{C}$ & 0.4 \\
Total & 44 & & 48 & & 51 & & 52 \\
Total & 44 & & 47 & & 48 & & 48 \\
selected & & & & & & \\
AIC & 13129.2 & & 11865.9 & & 11250.0 & & 11234.3 \\
\end{tabular}

estimates (Table 1). Whereas models for age and size were constructed with cohort $\left(F_{C}\right)$ as a class variable, models with age, size and condition were constructed with cohort $(C)$ as a continuous variable, to reliably reveal trends in the resultant 3-dimensional PMRNs.

(B) Annual increments: Annual length increments $\delta L$ were estimated as the differences in mean length between 2 consecutive ages of a cohort. The mean length at each age was calculated for each cohort from the back-calculated lengths. Annual weight increments $\delta W$ and annual changes $\delta K$ in condition factor between age groups of cohorts were estimated based on the otolith data combined with length-weight relationships estimated from the maturity data. From the otolith data, lengths at all ages for all individual fish for which otoliths had been measured were retrieved. Next, length-weight relationships were estimated for each year using a linear model with log-transformed weights and lengths. Fish younger than Age 4 were not representative for the length-weight relationship in the population, because the fishery selects for the larger individuals of these age groups. Relationships were thus based on Ages 4 to 10. There was a significant ( $\mathrm{p}<0.0001$ ) but small (absolute increase of $\mathrm{R}^{2}$ by 0.06) effect of age on the length-weight relationship. We thus chose to omit this small effect of age and extrapolated length-weight relationships to Ages 1 to 3. With these relationships, length-at-age from otolith readings was transformed to weight-at-age and condition at age for Ages 1 to 6 for each individual fish. Then, the average weight and condition of each age of each cohort was calculated and the annual weight increments $\delta W$ and changes $\delta K$ in condition factor were estimated as the differences in mean weight and condition, respectively, between 2 consecutive ages of a cohort. We assumed that increments were similar for all immature and mature individuals within an age group of a particular cohort. Obviously this assumption is not accurately met in a natural population but Barot et al. (2004a) showed that the method is not sensitive to violation of the assumption.

(C) Maturation probabilities: Eqs. (6) \& (7) were used to estimate the probabilities of maturation for each cohort, age and size class, with a resolution of $1 \mathrm{~cm}$ for length and of $1 \mathrm{~g}$ for weight. Linear interpolation was used, when necessary, to estimate the combinations of explanatory variables that yield a specific maturation probability (e.g. 10, 25, 50, 75 and 90\% denoted below by subscripts P10, P25, P50, P75 and P90 respectively). In particular, the term 'reaction norm midpoint' applies to the combinations of length, weight and/or condition that yield a maturation probability of $50 \%$ at a certain age.

(D) Confidence limits: In this step, a bootstrap analysis was carried out. A new dataset was created by choosing observations of individual fish chosen randomly from the maturity and otolith data with replacement. This selection was stratified by age and cohort such that the new dataset had the same number of samples per age and cohort. With the new dataset, the reaction norm midpoints were calculated for each age and cohort. This procedure was repeated 1000 times and the confidence limits of the reaction norm midpoints were approximated as the 2.5 and 97.5 percentiles of the distribution of the 1000 midpoints of each age and cohort (Manly 1997).

(E) Trends in maturation probabilities: The effect of cohort on reaction norm midpoints $\left(W_{\mathrm{P} 50}\right)$ of the 2dimensional PMRNs for age and weight was analysed per age group using a linear model with cohort as a continuous variable. In this model, the estimated reaction norm midpoints were weighted with the inverse of the variance of each midpoint, with the variance estimates being obtained from the bootstrap analysis. We could only demonstrate trends by showing PMRNs resulting from the beginning and end of our study period, because 3-dimensional PMRNs were constructed with cohort as a continuous variable and hence all parameters in these ogive models were continuous parameters. We chose to show results from cohorts 1960 and 1994 because from these cohorts sufficient fish were sampled to illustrate how observed sizes and conditions fit in the estimated PMRNs. 


\section{RESULTS}

Our analysis shows that individual weight is a slightly better variable than length for explaining the fraction of mature female plaice (Table 1). The maturity ogive model with cohort, age and length (Model 2, $123 \mathrm{df}$ ) accounted for $44 \%$ of the deviance, whereas the analogous model with weight instead of length (Model 3, $123 \mathrm{df}$ ) accounted for $48 \%$ of the deviance.

Including condition in addition to length or weight resulted in small increases of predictive power. The model with cohort, age, length and condition (Model 4, $165 \mathrm{df}$ ) accounted for $51 \%$ of the deviance, whereas the analogous model with weight instead of length accounted for $52 \%$ of the deviance (Model 5, 165 df). Table 1 shows that when length was used as the first component in the build-up of Model (4), inclusion of a single term for condition accounted for a further, statistically significant $6.1 \%$ of the deviance. Analogously, when weight was used as the first component in the build-up of Model (5), inclusion of a single term for condition accounted for an additional $1.1 \%$ of the deviance. Models in which condition was included (Models 4 \& 5) performed significantly better than models without (Models 2 \& 3; lower AIC values, significance based on chisquare test for likelihood-ratio test statistic, 165 df, p < 0.0001).

All estimated PMRNs turned out to have negative slopes, such that the weight and length at which plaice attain a certain probability of maturation decreases with age: in other words, at the same weight or length, older females have a higher maturation probability than younger ones (Fig. 2).

PMRNs for weight and age are much wider than PMRNs for length and age (Table 2). The difference between $W_{\text {P90 }}$ and $W_{\mathrm{P} 10}$ (averaged across all cohorts and expressed relative to $W_{\text {P50 }}$ on a logarithmic scale) ranges between 1.34 and 2.26 for the different age groups, whereas the corresponding difference between $L_{\mathrm{P} 90}$ and $L_{\mathrm{P} 10}$ only ranges between 0.41 and 0.47 (see Table 2 for details). The wider PMRNs for weight are to be expected given the curvilinearity in the weight-length relationship.
This can explain the difference in age group 3 and perhaps 4 , but not in the older age groups. The ratio of the width of the PMRNs for weight and length was close to the slope of the weight-length relationship (3.2) for Ages $3 \& 4$ (2.9 and 3.4 respectively), but exceeded this slope for Ages $5 \& 6$ (4.3 and 5.2 respectively). Moreover, the width of PMRNs for weight and age increases sharply with age, whereas the width of PMRNs for length and age is almost constant across all ages.
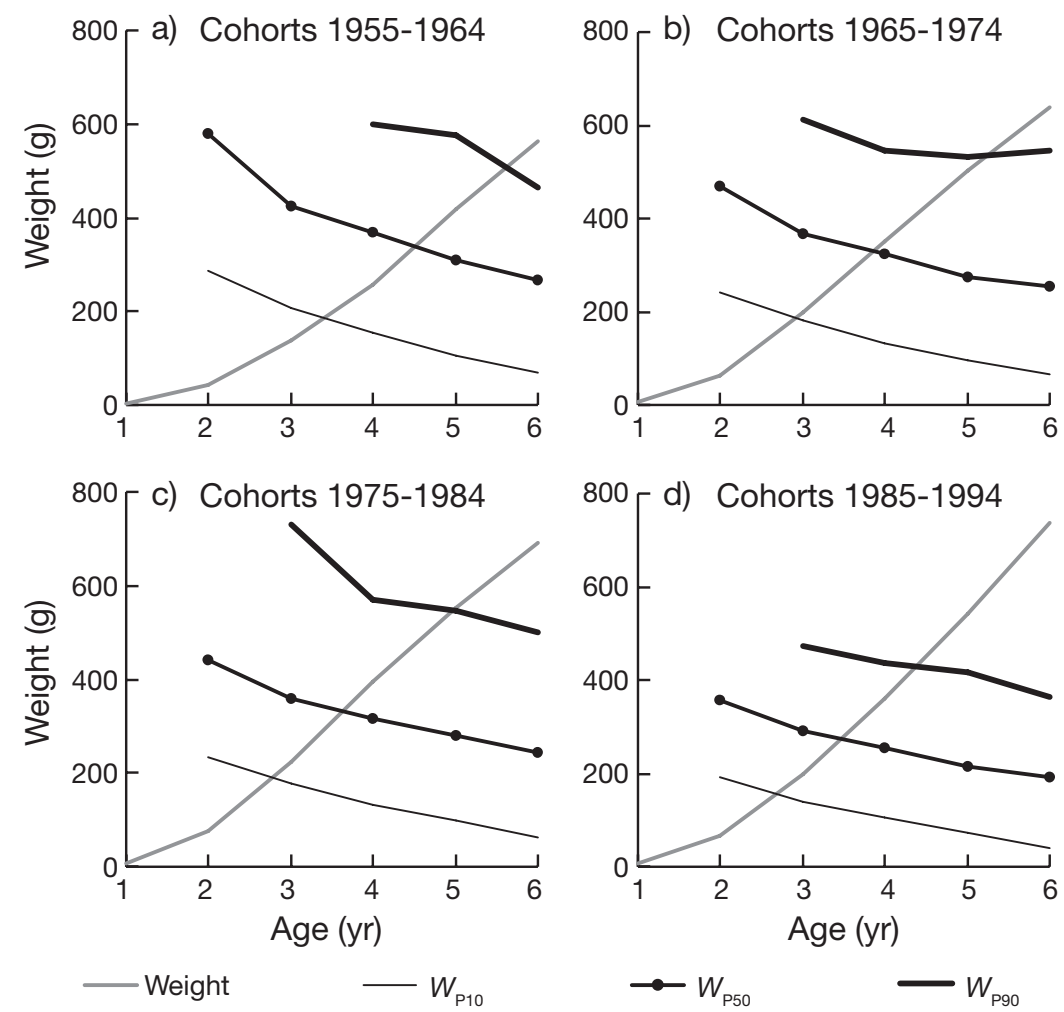

Fig. 2. Pleuronectes platessa. Probabilistic maturation reaction norms (PMRNs) and growth trajectories for weight and age. Weights at which probability of maturation reaches 10,50 and $90 \%\left(W_{\mathrm{P} 10}, W_{\mathrm{P} 50}, W_{\mathrm{P} 90}\right)$ shown as black curves of increasing thickness. Growth trajectories (grey curves) based on averaging agespecific weights across the cohorts indicated for each panel. Values of $W_{\text {P90 }}$ for

Age 2 in all periods and for Age 3 in the first period could not be estimated

Table 2. Pleuronectes platessa. Probabilistic widths of length- and weight-based PMRNs (log-scale) relative to average value of reaction norm midpoint: $L_{\mathrm{P} 50}$ or $W_{\text {P50. }}$. Widths averaged across all cohorts for each age group. Ratio: ratio between width of weight and length based PMRNs

\begin{tabular}{|cccccc|}
\hline Age & $\begin{array}{c}\text { PMRN for age and length } \\
L_{\mathrm{P} 50} \\
(\mathrm{~cm})\end{array}$ & $\begin{array}{c}\log L_{\mathrm{P} 90} / L_{\mathrm{P} 50} \\
-\log L_{\mathrm{P} 10} / L_{\mathrm{P} 50}\end{array}$ & $\begin{array}{c}W_{\mathrm{P} 50} \\
(\mathrm{~g})\end{array}$ & $\begin{array}{c}\log W_{\mathrm{P} 90} / W_{\mathrm{P} 50} \\
-\log W_{\mathrm{P} 10} / W_{\mathrm{P} 50}\end{array}$ & $\begin{array}{c}\text { Ratio } \\
\text { (width weight / } \\
\text { width length) }\end{array}$ \\
\hline 2 & 38.6 & 0.47 & 453 & n.a. & n.a. \\
3 & 34.6 & 0.45 & 357 & 1.34 & 2.94 \\
4 & 32.3 & 0.43 & 314 & 1.48 & 3.43 \\
5 & 30.7 & 0.41 & 269 & 1.75 & 4.27 \\
6 & 29.7 & 0.43 & 239 & 2.26 & 5.22 \\
\hline
\end{tabular}


Three-dimensional PMRNs show the additional effect of condition, on top of size and age, on the probability to mature. Results are shown for 2 selected cohorts only (Fig. 3). The isoprobability surfaces of this PMRN are tilted along the condition axis, resulting in a lower $S_{\mathrm{P} 50}$ at higher condition. This corroborates the expectation that female plaice of a certain length or weight and age will have a higher probability of maturation if they are in bet- a) Cohort 1960

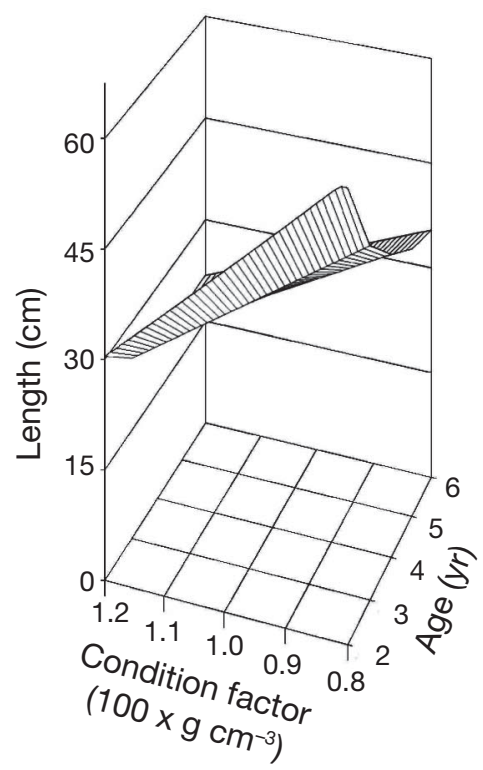

c) Cohort 1960)

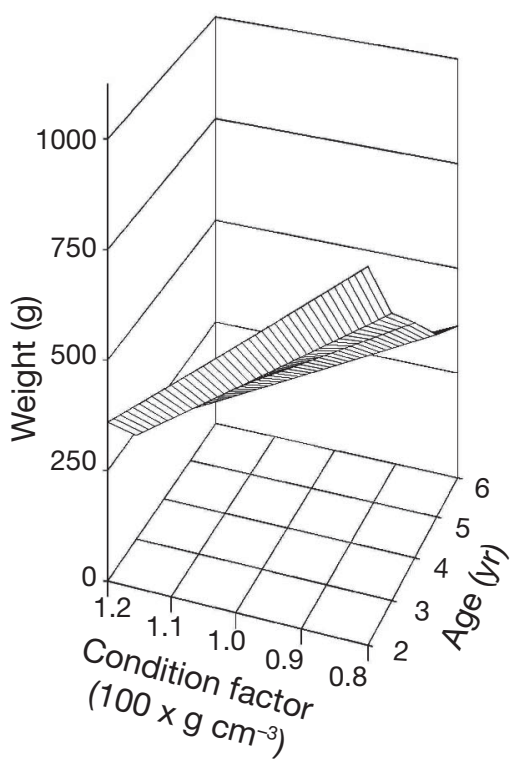

b) Cohort 1994

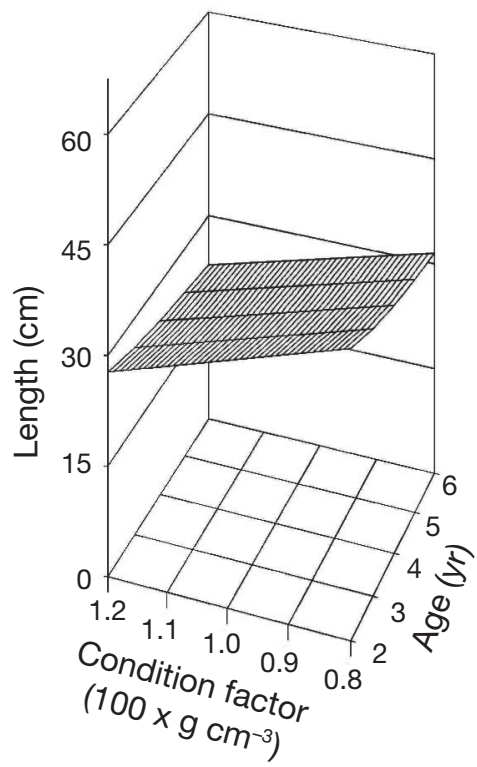

d) Cohort 1994

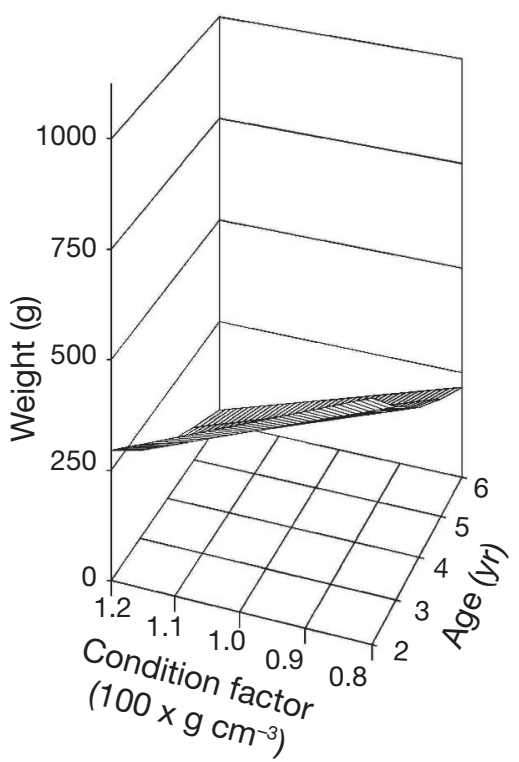

Fig. 3. Pleuronectes platessa. Three-dimensional probabilistic maturation reaction norms (PMRNs) for age, size and condition: length (top row); weight (bottom row). Midpoint surfaces indicate combinations of age, size and condition for which maturation probabilities equal 50\% for cohorts of 1960 (left) and 1994 (right) ter condition. Interestingly, this facilitating effect of good condition on maturation probability decreases with age. This can be seen more clearly when the 3-dimensional PMRNs are projected on the length-condition plane (Fig. 4): in both cohorts shown, the PMRN gets steeper with increasing age, indicating a weaker effect of condition on the probability of maturation. PMRNs based on weight give analogous results (Fig. 4).

Our analysis also revealed 3 interesting temporal trends, in the form of significant cohort effects. First, over the whole period and for all ages, the weight and length at which fish had a certain maturation probability decreased significantly (Fig. $5 ; \mathrm{R}^{2}=0.37$ to $0.54 ; \mathrm{p}<0.0001$ for all ages). Second, the width of both length- and weight-based PMRNs decreased significantly over time (Figs. $6 \& 7 ;$ p $<0.01$ for all ages, except for Age 2 where $p=0.07$ for trend in $\left.W_{\mathrm{P} 75}-W_{\mathrm{P} 25}\right)$. Third, the influence of both age and condition on maturation probability has decreased. The decreased contribution of age can be inferred from the fact that in both lengthbased and weight-based 3-dimensional PMRNs the midpoints of all ages have converged (Fig. 4). The decreased contribution of condition can be inferred from the fact that both length-based and weight-based PMRNs have become steeper (Figs. $4 \& 6$ ). There was a statistically significant $(p<0.0001)$ temporal trend in average condition, but it was very weak $\left(R^{2}=0.15 \%\right)$ and small (0.038 $\mathrm{g} \mathrm{cm}^{-3}$ per cohort). On average, the condition factor increased with $1.5 \%$ over the 41 cohorts studied.

\section{DISCUSSION}

\section{Weight vs. length as a measure of size}

Weight, as a measure of size for predicting maturation probabilities, offers one advantage over length in that ogive models for age and weight performed slightly but significantly better than ogive models for age and length. Although using weight as a measure of size yielded models that accounted for more variation based on the same degrees of freedom, this approach suffers from at least 2 drawbacks. 


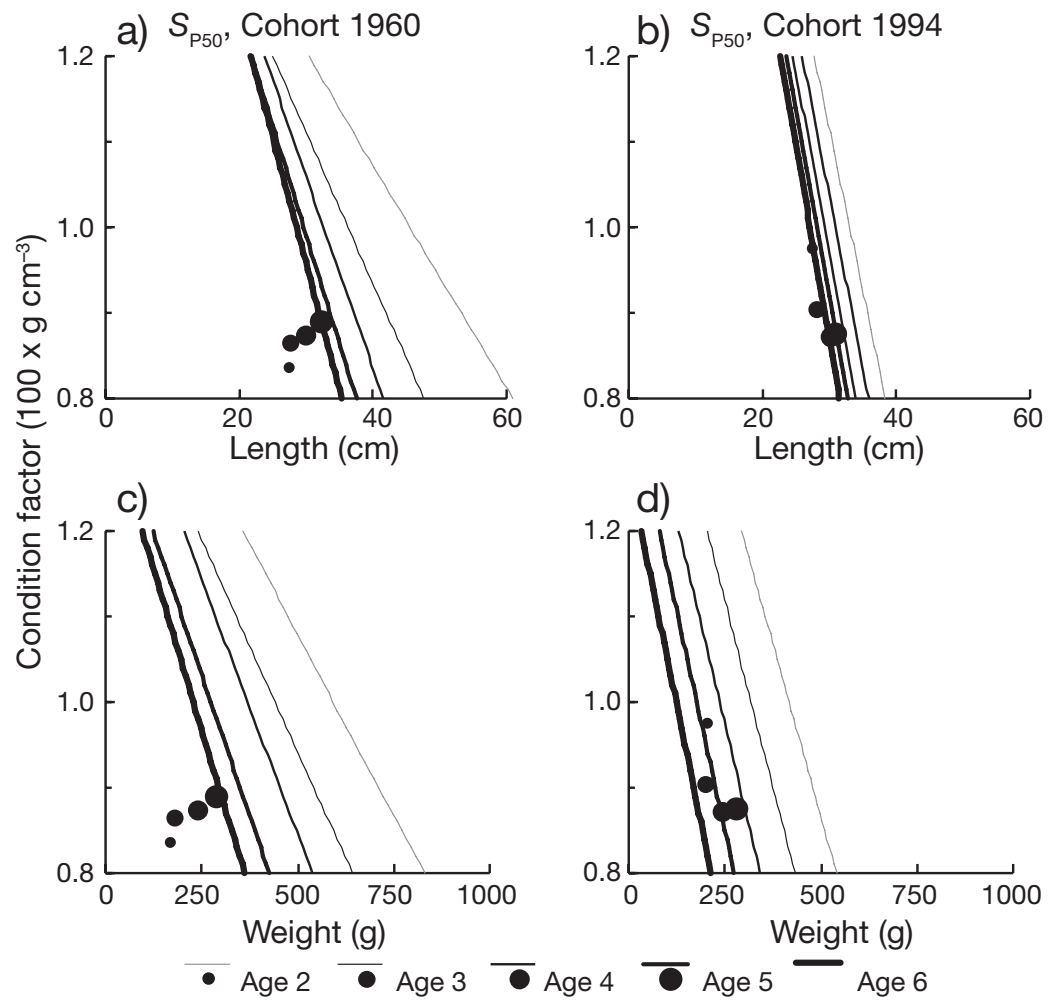

Fig. 4. Pleuronectes platessa. Projections of 3-dimensional probabilistic maturation reaction norms (PMRNs) for age, size and condition onto the size-condition plane: length (top row); weight (bottom row). Reaction norm midpoint lines shown for Ages 2 to 6 for cohorts of 1960 (left) and 1994 (right). Lines indicate, separately for each age, the combinations of size and condition for which maturation probability equals $50 \%$. 0 : median size and condition factor for each age group in that cohort; observations for Age 6 females did not occur in the dataset for either cohort
First, weight can vary much more significantly than length. The resulting fluctuations may reflect, for example, food conditions, reproductive stage and/or diseases. While these changes may well be caused by factors that are relevant for the onset of maturation, such as the level of body reserves, they may equally well be caused by factors that are completely irrelevant in that regard, such as current stomach content or the accumulation and release of eggs. In the analysis reported here, measured weights had to be normalized. While the need for this normalization seems incontrovertible, having to take decisions about how to accomplish it in practice is inconvenient and the uncertainty thus introduced is practically impossible to account for in the subsequent analyses. Length, in contrast, provides a more robust measure of size, as it is less sensitive to environmental fluctuations.

Second, length can only increase during the life of a fish, while weight can readily decrease. Since the state of maturity can be reached via diverse growth trajectories (Bernardo 1993) and since maturation probabilities average across all of them, the extra fluctuations a) Age 2

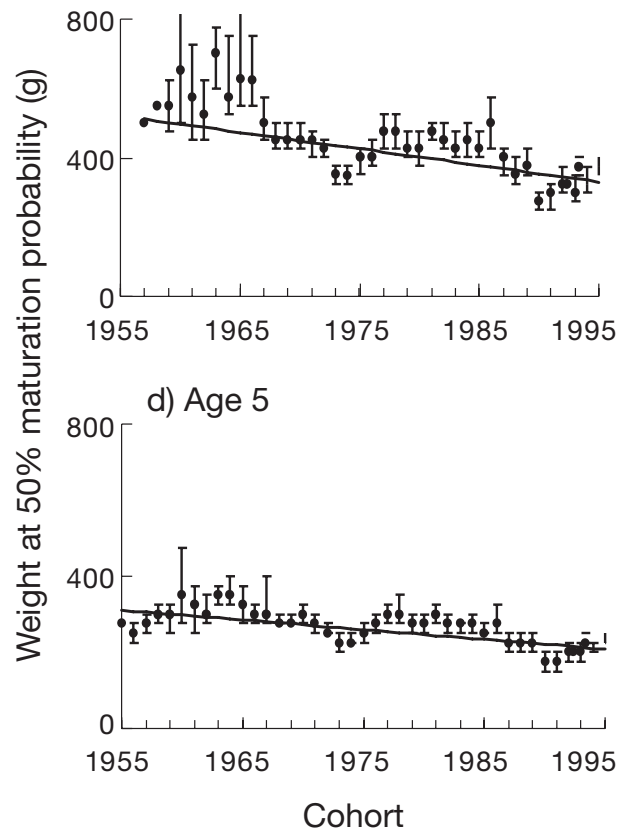

b) Age 3

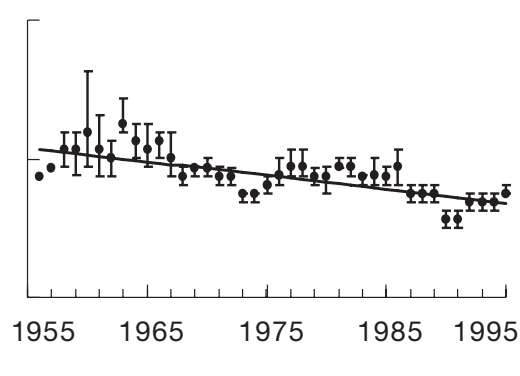

e) Age 6

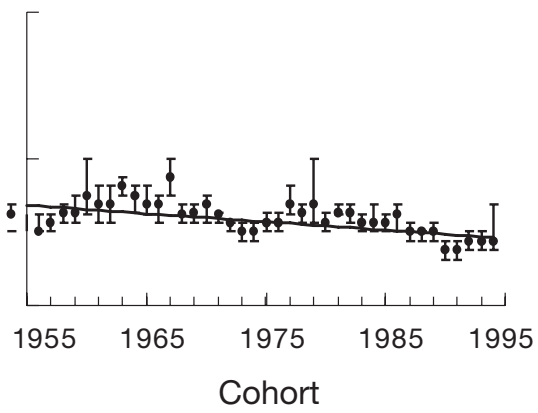

c) Age 4

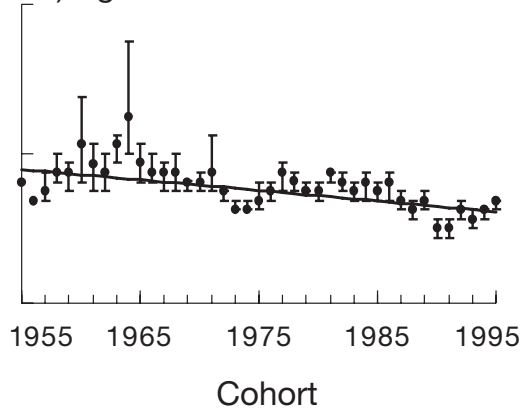

Fig. 5. Pleuronectes platessa. Trends in reaction norm midpoints $W_{\text {P50 }}(\bullet)$ and $95 \%$ confidence limits (error bars) for Ages 2 to 6 of all cohorts 
a) Age 3, Cohort 1960

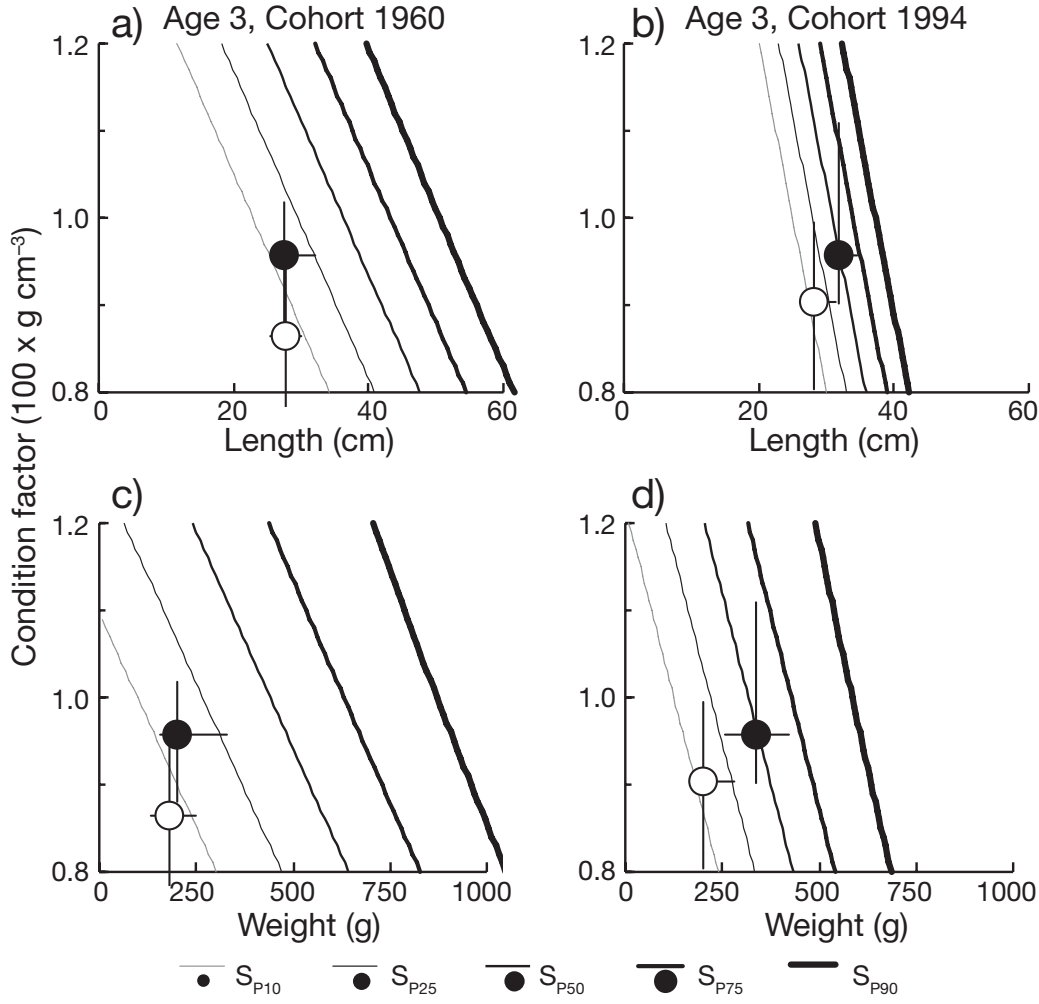

Fig. 6. Pleuronectes platessa. Projections of 3-dimensional probabilistic maturation reaction norms (PMRNs) for age, size and condition onto the size-condition plane: length (top row); weight (bottom row). Contours for 10, 25, 50, 75 and $90 \%$ maturation probability shown for Age 3 of cohorts 1960 (left) and 1994 (right). O: median size and condition factor for immature Age 3 females in the cohort, while attached whiskers indicate corresponding 10 and $90 \%$ percentiles.

-: same information for mature females

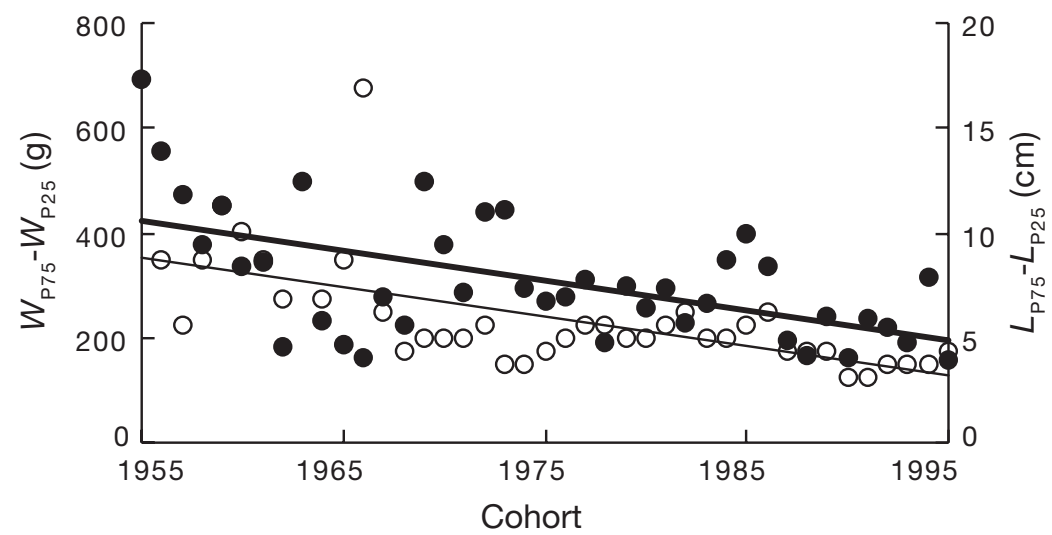

Fig. 7. Pleuronectes platessa. Trends in width of Age 3 probabilistic maturation reaction norms (PMRNs) for age and weight $(O$, thin line) and for age and length $\left(\bullet\right.$, thick line). $\mathrm{R}^{2}=0.15$ for $W_{\mathrm{P} 75}-W_{\mathrm{P} 25}, 0.31$ for $L_{\mathrm{P} 75}-L_{\mathrm{P} 25}$

in weight are bound to increase uncertainty in the estimation of maturation probabilities. A few studies of maturation processes do actually use fish weight as a measure of size (e.g. Cook et al. 1999, Bromley 2003) but these do not account for negative slopes in the growth trajectory. In accordance with these considera- tions, our results show that the relative widths of PMRNs for Age 5 and 6 are much higher when based on weight instead of on length. We also found that the widths of weight-based PMRNs increase sharply with age, which, for example, makes the extrapolation and interpolation of maturation probabilities across ages more problematic than it is for length-based PMRNs. In our opinion, considering these extra difficulties and balancing them against the only slightly elevated predictive power afforded by weight-based PMRNs in female plaice, this strengthens the case for length-based PMRNs.

\section{Impact of condition on maturation}

The 3-dimensional reaction norms confirm that good condition has a significant and positive effect on maturation, in line with earlier research (Rowe \& Thorpe 1991, Bohlin et al. 1994, Morgan 2004). While this is just as expected based on standard bioenergetic considerations, it has to be pointed out that in the present study an entirely different explanation based on the timing of measurements might also apply, as explained below.

In the data selected, maturation stage was measured during the spawning season, from January to March, rather than at the time at which plaice actually mature or initiate their maturation process: maturation starts in summer, when oocytes become vitellogenic (Rijnsdorp \& Witthames 2005). Both maturing and non-maturing plaice will still grow considerably thereafter, with maturing fish partitioning their surplus energy between somatic growth and energy reserves for reproduction, while the latter investment naturally is absent in nonmaturing fish. Since investment into reproduction increases the weight, but not the length, of fish at the time of spawning, it results in a higher condition factor $K$. Indeed, mature female plaice had a significantly higher condition factor than immature ones (comparison of means, $p<$ $0.0001, K=0.0102$ and $0.0094 \mathrm{~g} \mathrm{~cm}^{-3}$ respectively). This effect may contribute to the observed positive effect of condition on the probability of maturation. In this alter- 
native interpretation, the higher condition factor is not the cause but rather the consequence of maturation. Data on other measures of condition, such as liver weight, are not available for North Sea plaice. In flatfish, body condition is, however, a better indicator for the condition than liver weight because energy reserves are mainly stored in the soma (Dawson \& Grimm 1980, Morgan 2004) in contrast to, for instance, gadoids (Lambert \& Dutil 1997, Marshall et al. 1999).

Our finding that the facilitating effect of better condition on maturation decreases with age means that particularly young female plaice mature at earlier ages and smaller lengths when they have above-average condition, while older females in good and bad condition instead mature similarly. This agrees with observations on walleye, for which a good condition was found to increase the probability of maturation for younger females, while older females matured even if they were in poor condition (Henderson \& Morgan 2002). Similarly, turbot Scophthalmus maximus had a higher probability of maturing when they were fed well before maturation (Bromley et al. 2000). These findings can be interpreted by supposing that all these fish can mature at low age and small length only if they have ample surplus energy stores, whereas at higher ages they mature anyway, even if they suffer from relatively low energy reserves and even though the extra costs of reproduction may further decrease their survival rate. An understanding of these patterns is likely to relate to the so-called 'desperado' effect (Grafen 1987), through which an individual chooses a risky strategy due to a lack of alternative options.

\section{Interpretation of maturation trends}

Trends in the maturation process of North Sea plaice suggest that the trade-off between current and future reproduction of female plaice may have shifted to increased current reproduction through maturation at a very low age, size and body condition, thus decreasing the potential for future reproduction. This conclusion is based on 3 clear temporal trends: for all ages, the weight and length at which fish had a certain maturation probability have decreased significantly over time; the width of both length- and weight-based PMRNs have also decreased significantly; and the influence of both age and condition on maturation probability has decreased. Although the trend in weight at maturation (Fig. 5) was not corrected for any trend in condition factor, we believe that the small increase in average condition could only account for a minor part of the decreased $W_{\text {P50 }}$. Fig. 4 shows that the $1.5 \%$ by which condition factor increased over 41 cohorts would lead to a decrease in $W_{\mathrm{P} 50}$ of 3 to $4 \%$, whereas over all cohorts $W_{\text {P50 }}$ decreased by 32 to $37 \%$. The observed trends are in good agreement with a general prediction from life-history theory that if fish are faced with high adult mortality, such as in the North Sea plaice population, investment into future reproduction may not pay and, consequently, selection will not only favour earlier reproduction but also higher reproductive effort at age, at the expense of body growth and/or survival (Heino \& Kaitala 1999). We do not know if plaice is currently maturing at the lowest possible age, size and body condition, but we think that the narrow and steep reaction norms do not allow a strong continuation of the observed trends.

In a study based on the same dataset as was used here, an analysis trying to elucidate explicit fisheries-induced changes in reproductive investment in North Sea plaice remained inconclusive (Rijnsdorp et al. 2005). A review of fecundity and ovary weight data of female plaice from the literature, however, tentatively suggested that an increase in reproductive investment has occurred since the late 1940s. This finding is consistent with expectations based on the hypothesis of fisheries-induced evolutionary change (Rijnsdorp et al. 2005).

The question remains as to what extent observed changes in the maturation process are due to phenotypic plasticity or to genetic evolution. Our method has dealt with the phenotypically plastic response to varied growth and to variations in body condition, revealing a residual trend that, in the absence of alternative equally plausible explanations, suggests evolutionary changes in maturation. Possible factors that may influence the process of maturation other than through their effects on growth and condition, are temperature (Grift et al. 2003, Dhillon \& Fox 2004, Dembski et al. 2006) and social factors (Sohn 1977, Hobbs et al. 2004).

No observational study can exclude - as a matter of principle - the possibility that uncontrolled and potentially as yet unimagined, factors might fully account, through phenotypic plasticity, for the observed phenotypic trends in maturation. Conclusive proof of genetic evolution would require explicit data on changes in the sequences of genes together with functional insights into how such genetic changes affect maturation. Similarly, no observational study can ever unambiguously demonstrate that fisheries-induced selection is the cause of maturation trends, since observational studies can achieve no more than the establishment of suggestive correlations. Yet the present analysis, in conjunction with the consistency of patterns found in many studies based on other exploited species and on different parts of the oceans (e.g. Heino et al. 2002b, Barot et al. 2004b, 2005, Olsen et al. 2004, 2005) leads us to suggest that fisheries-induced evolution indeed offers the most parsimonious explanation of the residual trends reported here. 
Acknowledgements. We thank Bruno Ernande and Anssi Vainikka for helpful discussions. This study was financially supported by the Netherlands Organization for Scientific Research (NWO) and by the Netherlands Institute for Fisheries Research, by enabling a postdoctoral project of R.E.G. at IIASA. Additional financial support by the Austrian Federal Ministry of Education, Science and Cultural Affairs (U.D.); by the Austrian Science Fund, FWF (U.D.); the Research Council of Norway (M.H.); and by the European Research Training Network FishACE (Fisheries-induced Adaptive Changes in Exploited Stocks) is gratefully acknowledged. We thank Kentaro Morita and 2 anonymous referees for their constructive reviews.

\section{LITERATURE CITED}

Allison PD (1999) Logistic regression using the SAS system; theory and application, SAS, Cary, NC

Barot S, Heino M, Morgan MJ, Dieckmann U (2005) Maturation of Newfoundland American plaice (Hippoglossoides platessoides): long-term trends in maturation reaction norms despite low fishing mortality? ICES J Mar Sci 62: $56-64$

Barot S, Heino M, O'Brien L, Dieckmann U (2004a) Estimating reaction norms for age and size at maturation when age at first reproduction is unknown. Evol Ecol Res 6: $659-678$

Barot S, Heino M, O'Brien L, Dieckmann U (2004b) Longterm trend in the maturation reaction norm of two cod stocks. Ecol Appl 14:1257-1271

Bell G (1976) On breeding more than once. Am Nat 110:57-77

Bell G (1980) The costs of reproduction and their consequences. Am Nat 116:45-76

Bernardo J (1993) Determinants of maturation in animals. Trends Ecol Evol 8:166-173

Bohlin T, Dellefors C, Faremo U (1990) Large or small at maturity - theories on the choice of alternative male strategies in anadromous salmonids. Ann Zool Fenn 27:139-147

Bohlin T, Dellefors C, Faremo U (1994) Probability of first sexual maturation of male parr in wild sea-run brown trout (Salmo trutta) depends on condition factor $1 \mathrm{yr}$ in advance. Can J Fish Aquat Sci 51:1920-1926

Borisov VM (1978) The selective effect of fishing on the population structure of species with long life cycle. J Ichthyol 18:896-904

Bromley PJ (2003) The use of market sampling to generate maturity ogives and to investigate growth, sexual dimorphism and reproductive strategy in central and southwestern North Sea sole (Solea solea L.). ICES J Mar Sci 60:52-65

Bromley PJ, Ravier C, Witthames PR (2000) The influence of feeding regime on sexual maturation, fecundity and atresia in first-time spawning turbot. J Fish Biol 56:264-278

Cook RM, Kunzlik PA, Hislop JRG, Poulding D (1999) Models of growth and maturity for North Sea Cod. J Northwest Atl Fish Sci 25:91-99

Dawson AS, Grimm AS (1980) Quantitative changes in the protein, lipid and energy content of the carcass, ovaries and liver of adult female plaice, Pleuronectes platessa L. J Fish Biol 16:493-504

Dembski S, Masson G, Monnier D, Wagner P, Pihan JC (2006) Consequences of elevated temperatures on life-history traits of an introduced fish, pumpkinseed Lepomis gibbosus. J Fish Biol 69:331-346

Dhillon RS, Fox MG (2004) Growth-independent effects of temperature on age and size at maturity in Japanese Medaka (Oryzias latipes). Copeia 2004:37-45
Grafen A (1987) The logic of divisively asymmetric contests respect for ownership and the desperado effect. Anim Behav 35:462-467

Grift RE, Rijnsdorp AD, Barot S, Heino M, Dieckmann U (2003) Fisheries-induced trends in reaction norms for maturation in North Sea plaice. Mar Ecol Prog Ser 257:247-257

Heino M, Dieckmann U, Godø OR (2002a) Measuring probabilistic reaction norms for age and size at maturation. Evolution 56:669-678

Heino M, Dieckmann U, Godø OR (2002b) Reaction norm analysis of fisheries-induced adaptive change and the case of the Northeast Arctic cod. ICES CM 2002/Y:14:1-14

Heino M, Godø OR (2002) Fisheries-induced selection pressures in the context of sustainable fisheries. Bull Mar Sci 70: 639-656

Heino M, Kaitala V (1999) Evolution of resource allocation between growth and reproduction in animals with indeterminate growth. J Evol Biol 12:423-429

Henderson BA, Morgan GE (2002) Maturation of walleye by age, size and surplus energy. J Fish Biol 61:999-1011

Hobbs JPA, Munday PL, Jones GP (2004) Social induction of maturation and sex determination in a coral reef fish. Proc R Soc London B 271:2109-2114

Hosmer DW, Lemeshow S (2000) Applied logistic regression, John Wiley \& Sons, New York

Hutchings JA (1993) Adaptive life histories effected by agespecific survival and growth rate. Ecology 74:673-684

Lambert Y, Dutil JD (1997) Can simple condition indices be used to monitor and quantify seasonal changes in the energy reserves of Atlantic cod (Gadus morhua)? Can J Fish Aquat Sci 54:104-112

Law R (2000) Fishing, selection, and phenotypic evolution. ICES J Mar Sci 57:659-668

Manly BFJ (1997) Randomization, bootstrap and monte carlo methods in biology, Chapman \& Hall, London

Marshall CT, Yaragina NA, Lambert Y, Kjesbu OS (1999) Total lipid energy as a proxy for total egg production by fish stocks. Nature 402:288-290

Marteinsdottir G, Begg GA (2002) Essential relationships incorporating the influence of age, size and condition on variables required for estimation of reproductive potential in Atlantic cod Gadus morhua. Mar Ecol Prog Ser 235: $235-256$

Morgan MJ (2004) The relationship between condition and the probability of being mature in American plaice (Hippoglossoides platessoides). ICES J Mar Sci 61:64-70

Olsen EM, Heino M, Lilly GR, Morgan MJ, Brattey J, Ernande B, Dieckmann U (2004) Maturation trends indicative of rapid evolution preceded the collapse of northern cod. Nature 428:932-935

Olsen EM, Lilly GR, Heino M, Morgan MJ, Brattey J, Dieckmann U (2005) Assessing changes in age and size at maturation in collapsing populations of Atlantic cod (Gadus morhua). Can J Fish Aquat Sci 62:811-823

Reznick D (1983) The structure of guppy life histories - the tradeoff between growth and reproduction. Ecology 64:862-873

Reznick DN, Bryga H, Endler JA (1990) Experimentally induced life-history evolution in a natural population. Nature 346:357-359

Reznick DN, Shaw FH, Rodd FH, Shaw RG (1997) Evaluation of the rate of evolution in natural populations of guppies (Poecilia reticulata). Science 275:1934-1936

Rijnsdorp AD (1989) Maturation of male and female North Sea plaice (Pleuronectes platessa L.). J Cons Int Explor Mer 46: $35-51$ 
Rijnsdorp AD (1993) Fisheries as a large-scale experiment on life-history evolution: disentangling phenotypic and genetic effects in changes in maturation and reproduction of North Sea plaice, Pleuronectes platessa L. Oecologia 96:391-401

Rijnsdorp AD, Ibelings B (1989) Sexual dimorphism in the energetics of reproduction and growth of North Sea plaice, Pleuronectes platessa L. J Fish Biol 35:401-415

Rijnsdorp AD, Millner RS (1996) Trends in population dynamics and exploitation of North Sea plaice (Pleuronectes platessa L.) since the late 1800s. ICES J Mar Sci 53: $1170-1184$

Rijnsdorp AD, Van Leeuwen PI (1992) Density-dependent and independent changes in somatic growth of female North Sea plaice Pleuronectes platessa between 1930 and 1985 as revealed by back-calculations of otoliths. Mar Ecol Prog Ser 88:19-32

Rijnsdorp AD, Van Leeuwen PI (1996) Changes in growth of North Sea plaice since 1950 in relation to density, eutrophication, beam-trawl effort, and temperature. ICES J Mar Sci 53:1199-1213

Rijnsdorp AD, Van Leeuwen PI, Visser TAM (1990) On the validity and precision of back-calculation of growth from otoliths of the plaice (Pleuronectes platessa L.). Fish Res 9: 97-117

Rijnsdorp AD, Grift RE, Kraak SBM (2005) Fisheries-induced adaptive change in reproductive investment in North Sea

Editorial responsibility: Otto Kinne (Editor-in-Chief), Oldendorf/Luhe, Germany plaice (Pleuronectes platessa)? Can J Fish Aquat Sci 62: 833-843

Rijnsdorp AD, Witthames PR (2005) Ecology of reproduction. In: Gibson RN (ed) The biology of flatfish. Blackwell Scientific, London, p 68-93

Rowe DK, Thorpe JE (1991) Role of fat stores in the maturation of male Atlantic salmon (Salmo salar) parr. Can J Fish Aquat Sci 48:405-413

Royston P, Altman DG (1994) Regression using fractional polynomials of continuous covariates: parsimonious parametric modelling. Appl Stat 43:429-467

Siems DP, Sikes RS (1998) Tradeoffs between growth and reproduction in response to temporal variation in food supply. Environ Biol Fishes 53:319-329

Simpson AL (1992) Differences in body size and lipid reserves between maturing and nonmaturing Atlantic salmon parr, Salmo salar L. Can J Zool 70:1737-1742

Sohn JJ (1977) Socially induced inhibition of genetically determined maturation in the platyfish, Xiphophorus maculatus. Science 195:1999-1200

Stearns SC, Koella JC (1986) The evolution of phenotypic plasticity in life-history traits: predictions of reaction norms for age and size at maturity. Evolution 40:893-913

Van Dooren TJM, Tully T, Ferriere R (2005) The analysis of reaction norms for age and size at maturity using maturation rate models. Evolution 59:500-506

Submitted: May 22, 2006; Accepted: September 28, 2006 Proofs received from author(s): February 23, 2007 